\title{
Effect of Polypropylene Fibre on Engineering Properties of Bitumen and Bituminous Mix

\author{
${ }^{* 1}$ Varsha Harne, ${ }^{2}$ Anuj Kumar Sharma, ${ }^{3}$ Kameshwar Rao Tallapragada ${ }^{4}$ Surbhi Mewara \\ 1,2,3,4 Shri Ramdeobaba College of Engineering and Management, Nagpur \\ Email:harnevr@rknec.edu,sharmaak@rknec.edu,raotk@rknec.edu,mewarasurbhil@gmail.com
}

Received: 07th November 2019, Accepted: 31st January 2020, Published: 29th February 2020

\begin{abstract}
The problems related with the bituminous pavements are their premature distress in the form of cracks, ravelling, surface undulations and segregation. This results in huge maintenance cost.To minimize the maintenance cost, the proper quality of work and material is important. Improving the qualities of bitumen and improving the stability of bituminous mixes may be one of the solutions. This paper deals with use of polypropylene fiber as an admixture to bitumen. Various tests on bitumen and polypropylene added bitumen was conducted to compare the properties. Few tests on bituminous mixes were also performed to adjudge the effect of different percentages of fibers on mixes. Marshall's stability tests were conducted to determine the optimum binder content. By varying the amount of $20 \mathrm{~mm}$ polypropylene fibers $(3 \%, 5 \%$, and $7 \%$ by weight of bitumen), optimum fiber content was obtained. The results indicate that the addition of PP fibers increases the stability but decreases the flow value.
\end{abstract}

\section{Keywords}

Bitumen, Polypropylene, Marshal Stability, Softening Point, Ductility

\section{Introduction}

Highways are a fundamental infrastructure in the national economy and social welfare, since they provide mobility and accessibility for motorists and goods. The roads with higher volume of traffic and increased axle loads of heavy vehicles, the use of fibres comes out as a need for improving the flexibility and tensile strength of the bituminous mixtures. These are some of the causes which lead to the premature distress of bituminous mixtures in road pavements, namely cracking and rutting. Furthermore, mixtures with fibres can be submitted to high and low temperatures without losing their efficiency and with no distresses.[10]

The conventional bituminous mixes are subjected to various types of failures like cracks because of low fatigue strength, and failures like bleeding, and disintegration because of lower susceptibility to climatic changes.[6][14]

At present, the maintenance cost is higher so now the method of maintenance has to be modified for the flexible pavement. To avoid the maintenance cost, the proper quality of work and material is important. So to improve the quality, various material or chemicals are used to improve the quality or to improve the property of the raw material. The study is about to improve the properties of bitumen.

The properties of bitumen and bituminous mixes need to be improved to have better resistance against temperature variation.

Addition of synthetic fibres is one of the ways to improve the engineering properties of material and mixes.[5][11] Polypropylene synthetic fibre [1] is one of such product which can be used as an additive to bitumen.

Depending upon the type of polypropylene fibre, it shrinks 5 to $12 \%$ at temperature above $100^{\circ} \mathrm{C}$ and softens at temperature about $140^{\circ} \mathrm{C}, \&$ melts at temperature above $160^{\circ} \mathrm{C}$ and decomposes at temperature $288^{\circ} \mathrm{C}$.

The properties of Polypropylene [2] which qualify it to be a good modifier are:

- $\quad$ Polypropylene is a light fibre. It is easy to process and ensures high processing yields

- Its cost is lower than that of polyester and nylon fibre.

- Good heat resistance. Have a binding property hence used as a binder.

- Tough, Good fatigue resistance, Higher softening point

Objectives

The Objectives of this study are:

1. To experiment the use of Polypropylene fibre in bituminous concrete mixes

2. To check the effect of different percentages of fibres in engineering properties of bitumen and bituminous concrete

3. To optimize the percentage of fibre for better results 


\section{Study Approach}

The experimental work was divided in to four distinct stages (i) Problem Definition (ii) Identifying the materials required (iii) tests on materials (iv) test on bituminous mixes to optimize the fibre content (v) interpretation of test results and conclusions. Fig. below shows the schematic diagram of experimentation program.

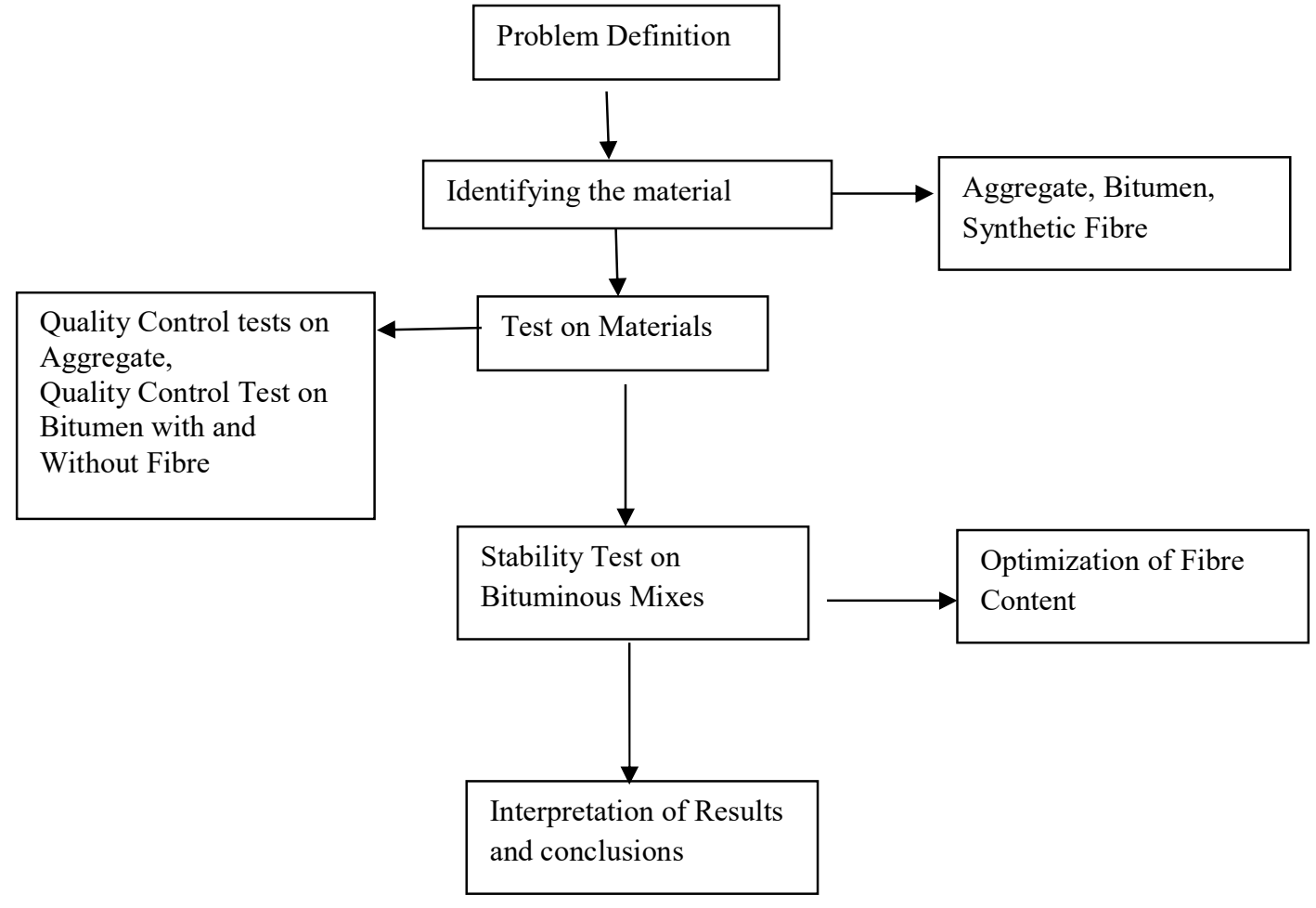

Figure 1: Schematic Diagram of Experimentation Program

\section{Laboratory Investigations}

The laboratory tests were performed on aggregates, bitumen and bituminous mixes with and without fibre. The tests which were performed on aggregate to check their suitability includes sieve analysis, shape test, impact value test, abrasion value test, crushing value test, specific gravity testy and water absorption test. The tests which were performed on bitumen which includes penetration test, ductility test, softening point test, and specific gravity test with and without fibres.[4]

Marshal method of bituminous mix design was used to design the mixes with and without fibres and to decide the optimum content of fibre to be mixed with bitumen for the best result.[3][12]

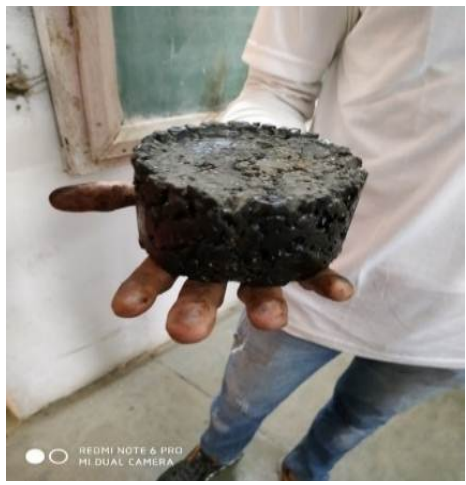

Figure 2: Marshal Sample

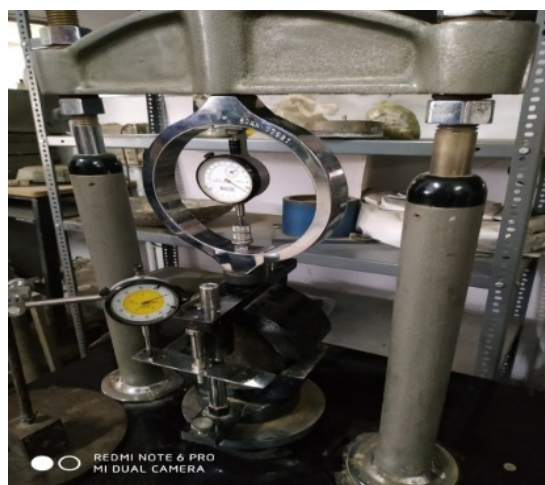

Figure 3: Marshal Test 
Test Results

\begin{tabular}{|l|l|}
\hline Sieve size & percentage Passing \\
\hline 25 & 100 \\
\hline 20 & 97.5 \\
\hline 12.5 & 72 \\
\hline 10 & 63 \\
\hline 4.75 & 38 \\
\hline 2.36 & 28 \\
\hline 1.18 & 12 \\
\hline 0.075 & 4 \\
\hline
\end{tabular}

\begin{tabular}{|c|c|c|}
\hline \multicolumn{3}{|c|}{ Table 1: Aggregate Grading } \\
\hline Name of Test & IS Code used for testing & Result Obtained \\
\hline Impact & IS:2386 & $13.8 \%$ \\
\hline Abrasion & IS:2386 & $19.1 \%$ \\
\hline Water absorption & IS:2386 & $\mathbf{0 . 6 7 \%}$ \\
\hline Specific Gravity & IS:2386 & $\mathbf{2 . 6 1}$ \\
\hline $\begin{array}{c}\text { Combined Elongation \& } \\
\text { Flakiness Index }\end{array}$ & IS:2386 & $\mathbf{2 3 . 4 3 \%}$ \\
\hline Crushing value & IS:2386 & $\mathbf{1 7 . 8 \%}$ \\
\hline
\end{tabular}

Table 2: Physical Properties of Aggregates

\begin{tabular}{|c|c|c|}
\hline Name of Test & Fibre \% by weight of bitumen & Result \\
\hline Penetration Test & $0 \%$ & 65.67 \\
\hline & $3 \%$ & 64 \\
\hline & $5 \%$ & 62.33 \\
\hline & $7 \%$ & 61 \\
\hline Softening Point & $0 \%$ & 49.67 Degree C \\
\hline & $3 \%$ & 66.63 Degree C \\
\hline & $5 \%$ & 76 Degree C \\
\hline & $7 \%$ & 82.33 Degree C \\
\hline Ductility Test & $0 \%$ & $55.67 \mathrm{~cm}$ \\
\hline & $3 \%$ & $49.33 \mathrm{~cm}$ \\
\hline & $5 \%$ & $45.66 \mathrm{~cm}$ \\
\hline & $7 \%$ & $42.33 \mathrm{~cm}$ \\
\hline
\end{tabular}

Table 3: Properties of Bitumen



Figure 4: \% Bitumen vs Marshall Stability

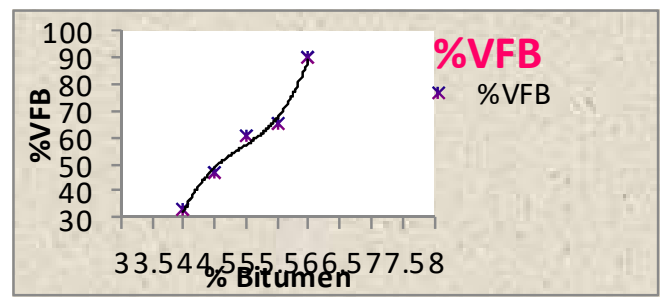

Figure 6: \% Bitumen vs \%VFB

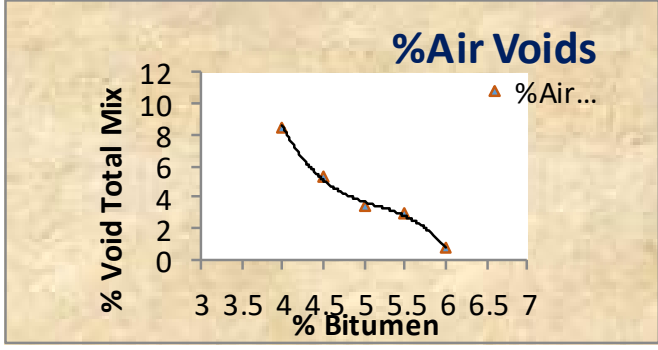

Figure 5: \% Bitumen vs \% Void Total Mix

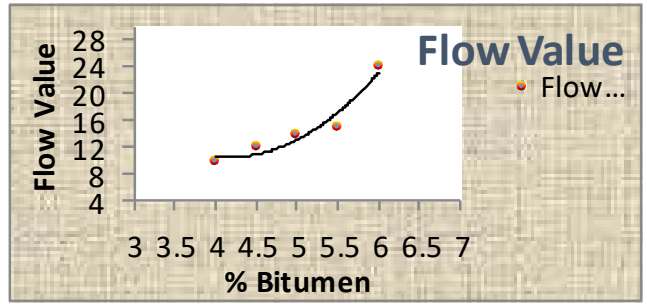

Figure 7: \% Bitumen vs Flow Value 


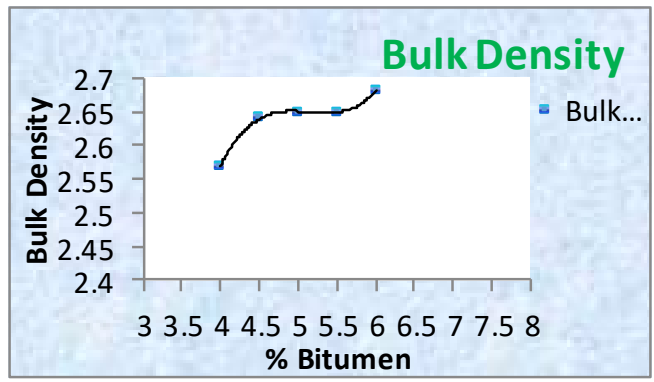

Figure 8: \% Bitumen vs Bulk Density

Optimum binder content without fibre was found to be $4.5 \%$ with a Marshall Stability value of $926.9 \mathrm{~kg}$.

\begin{tabular}{|c|c|c|c|c|c|}
\hline \multirow{2}{*}{$\begin{array}{l}\text { Fibre by } \\
\text { weight of } \\
\text { bitumen }(\%)\end{array}$} & \multirow{2}{*}{$\begin{array}{l}\text { Bitumen by } \\
\text { weight of } \\
\text { aggregate }(\%)\end{array}$} & \multicolumn{2}{|c|}{ Marshall value (kg) } & \multicolumn{2}{|c|}{ Flow value (0.25mm unit) } \\
\hline & & Observed & Average & Observed & Average \\
\hline 0 & 4.5 & 878.30 & \multirow[t]{3}{*}{926.9} & 14.4 & \multirow[t]{3}{*}{14.30} \\
\hline 0 & 4.5 & 1021.50 & & 16.5 & \\
\hline 0 & 4.5 & 880.90 & & 12 & \\
\hline 2 & 4.5 & 1159.72 & \multirow[t]{3}{*}{1197.81} & 12.4 & \multirow[t]{3}{*}{13.43} \\
\hline 2 & 4.5 & 1296.20 & & 13.7 & \\
\hline 2 & 4.5 & 1137.50 & & 14.2 & \\
\hline 3 & 4.5 & 1278 & \multirow[t]{3}{*}{1245.00} & 11.8 & \multirow[t]{3}{*}{13.17} \\
\hline 3 & 4.5 & 1190 & & 13.2 & \\
\hline 3 & 4.5 & 1267 & & 14.5 & \\
\hline 5 & 4.5 & 1326 & \multirow[t]{3}{*}{1294.00} & 12.0 & \multirow[t]{3}{*}{12.37} \\
\hline 5 & 4.5 & 1178 & & 11.3 & \\
\hline 5 & 4.5 & 1378 & & 13.8 & \\
\hline 7 & 4.5 & 1321.91 & \multirow[t]{3}{*}{1278.70} & 13.2 & \multirow[t]{3}{*}{12.20} \\
\hline 7 & 4.5 & 1230.20 & & 12.4 & \\
\hline 7 & 4.5 & 1284 & & 11.0 & \\
\hline
\end{tabular}

Table 4: Marshall Mix Design (with different \% of Fibres)

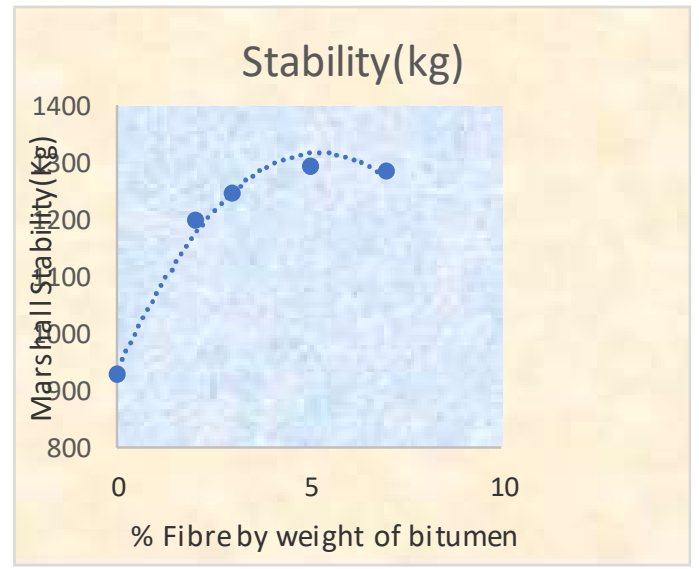

Figure 9: \% Fibre vs Stability

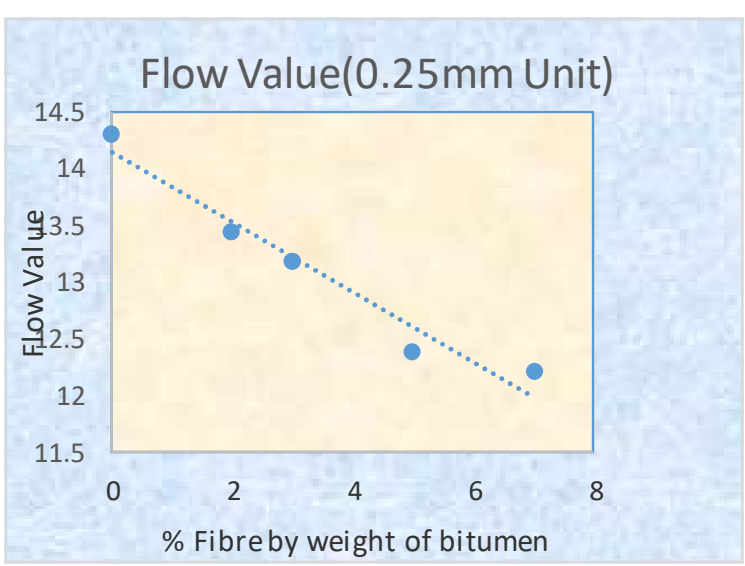

Figure 10: \% Fibre vs Flow Value

\section{Conclusion}

- The optimum percentage of polypropylene fibre was found to be $5 \%$ by weight of bitumen in this study.

- Modified bituminous concrete with $4.5 \%$ bitumen and $5 \%$ polypropylene fibre increased the stability value by about $40 \%$.

- Softening point increased by $35 \%$ than that of conventional bitumen.

- Ductility decreased by $17 \%$ than that of unmodified bitumen. 
- Penetration decreased by $5 \%$ than that of unmodified bitumen.

- The addition of 5\% PP fibres to bituminous mixtures increased the Marshall Stability value and decreased the flow value, but within prescribed limits specified in the design procedure.

- Increase in fibre content more than 5\% resulted in not much variation in stability or flow value.

The variation in stability will improves the structural resistance of bituminous concrete to distresses occurring in flexible pavements. Increased softening point suggests that the mix will be less susceptible to temperature variation. This will reduce problems like bleeding, segregation etc. Addition of polypropylene fibres may increase the overall performance of mix in the field. But it has to be verified by using the mix in the field and observing its performance.

\section{References}

1. Abdelaziz Mahrez, Herda Yati Katman, Mohamed Rehan Karim "Fatigue And Deformation Properties Of Glass Fibre Reinforced Bituminous Mixes", Journal of the Eastern Asia Society for Transportation Studies, Vol. 6, pp. 997 - 1007, 2005

2. Concrete Mix" International Journal of Engineering Research \& Technology (IJERT)ISSN: 22780181,Vol. 4 Issue 02 February-2015

3. Garnepudi Sandeep, M Srinivasa Reddy "Experimental Study Of Bituminous Mixes Using Natural Fibre",International Journal of Advance Engineering and Research Development Volume 4, Issue 2, February -2017 (Scopus-IRJET)

4. https://en.wikipedia.org/wiki/Polypropylene

5. IRC SP53:2010

6. IS Code 2386

7. Miss Apurva J Chavan "Use Of Plastic Waste In Flexible Pavements", International journal of innovation in Engineering and management Volume 2, Issue 4, April 2013 (Scopus-IRJET)

8. MohdAdliSani, Abi Zaid AbdLatib, Choy Peng NG, Mohammed Alias Yusof, Nordila Ahmad, MohdAmzari Mat Rani "Properties of Coir Fibre and Kenaf Fibre Modified Asphalt Mixes", Journal of the Eastern Asia Society for Transportation Studies, Vol.9, 2011

9. Saswat Biswapriya Dash and Mahabir Panda "A Study on Use of Natural Fibre for Improvement in Engineering Properties of Dense Graded Bituminous Mixes with Coal Ash", Springer International Publishing Switzerland, 2 February 2016 (Springer)

10. Serkan Tapkin "The effect of polypropylene fibers on asphalt performance" June 2008 Building and Environment 43(6):1065-1071.

11. Suresh.T, Gobinath.R, Kannan.T , Saranya.S, Sruthy Radhakrishnan , NeelimaSinghvi , Chitravel.V, "Studies on Modifying Strength Parameters of Bitumen Using Fibres" International Journal of Engineering Research \& Technology Vol. 2 Issue 10, October - 2013 (IJRET)

12. T.Suresh, T.J.Vijay, A Chandrasekar "Modeling Marshall Stability Of Coir Fibre Reinforced Asphalt Concrete", International Research Journal of Engineering and Technology (IRJET) Volume: 03 Issue: | Nov-2016 (Scopus-IRJET)

13. Text book of Highway Engineering by S.K Khanna \& C.E . Justo

14. Yassir Nashaat A. Kareem et.al "Fatigue Behavior of Polypropylene Fiber Reinforced Bituminous concrete mix." International Journal of Engineering Research \& Technology (IJERT) 4 (2015) 